\title{
Evaluation of the Effectiveness of Cereal Bran Extract for Sunflower Oil Stability during Frying
}

\author{
Abayomi W. Ajala ${ }^{\mathrm{a}}$ And Abdollah Ghavami ${ }^{\mathrm{b}^{*}}$ \\ ${ }^{a}$ School of Human Sciences - London Metropolitan University, 166-220 Holloway Road - London N7 8DB \\ United Kingdom \\ ${ }^{*}$ Corresponding author \\ a.ghavami@londonmet.ac.uk \\ TEL: $+44(0) 2071332589$
}

Received: 19 October 2018; Published online: 18 January 2020

\begin{abstract}
This study evaluated the effectiveness of black rice, millet and barley bran extracts against oxidative degradation of sunflower oil in frying, by determining the total antioxidant activity, total phenolic content, free fatty acid content, conjugated diene content and total polar content. It was reported that the total phenolic content rice bran was approximately three times higher than that of the millet bran extracts and five times higher than the results for barley bran extracts. The total antioxidant activity results for barley bran and rice bran extract (40.95 \pm 0.07 and $40.87 \pm 0.04$ Trolox equivalent $\mu \mathrm{mol} / \mathrm{g}$ of bran, respectively) were two times higher than that of millet bran extract $(17.16 \pm 0.34$ Trolox equivalent $\mu \mathrm{mol} / \mathrm{g}$ of bran). The results of the effectiveness of the cereal bran extracts were significantly different $(\mathrm{p}<0.05)$. The free fatty acid content of the rice bran and propyl gallate enriched oil samples showed better results $(2.02 \pm 0.01 \%$ and $1.62 \pm 0.00 \%)$ than millet, barley and control enriched oil samples $(3.43 \pm 0.01 \%, 3.13 \pm 0.01 \%$ and $6.13 \pm 0.01 \%$ respectively). In the same vein, conjugated diene content results from all the enriched oil samples indicated that the rice bran enriched oil sample had the least amount of secondary oxidized products compared to the other enriched oil samples. It can be concluded that rice bran extract can be used for frying without discarding or replenishing the oil.
\end{abstract}

Keywords: Bran extracts; Antioxidant; Oil Stability; Propyl gallate

\section{Introduction}

Hydrolysis, oxidation and polymerization are the most prominent chemical reactions that occur in the deep-fat frying process and the resulting products from these reactions adversely affect the flavor, quality of oil, the nutritional composition and safety of the fried food (Sumnu \& Sahin, 2008). Free fatty acids, aldehyde, ketone, triglyceride, monoglyceride, cyclic and epoxy compounds, trans-isomers, dimer and oligomer are the primary resulting organic compounds from the series of chemical reactions mentioned above that do affect the safety and quality of the frying oil (Choe \& Min, 2007).

Over the years, different oxidative-controlling methods have been used, such as nitrogen and carbon dioxide blanketing, vacuum frying, and the use of genetically modified oil. Addition of antioxidants has been developed to reduce the extent to which oxidative degradation reactions occur in oil during frying (Aladedunye, Matthäus \& Przybylski, 2011), however, it was discovered that the addition of an antioxidant was both effective against oxidation in oil and cost efficient. Butylated hydroxy- 


\section{Nomenclature}

\section{FFA Free Fatty Acid}

TEAC Trolox equivalent antioxidant capacity

TPC Total phenolic content

TPM Total polar material
PG Propyl gallate

RBE Rice bran extracts

MBE Millet bran extracts

BBE Barley bran extracts toluene (BHT) and butylated hydroxyanisole (BHA), tertiary butylhydroquinone (TBHQ), 2tert-butyl-4-methylphenol (TBMP), and propyl gallate $(\mathrm{PG})$ are common examples of the antioxidants used in the vegetable oil industry (Pokorny, Yanishlieva \& Gordon, 2001). Although, the application of these synthetic antioxidants to vegetable oils during frying had been effective at 200 ppm Codex Alimentarius standard over the years, there is a growing concern about safety due to some toxicological reports (Okubo, Yokoyama, Kano \& Kano, 2003). This contributed to a consumer-initiated trend called "clean labeling" which simply demands that the majority of food additives should be replaced with ones from natural sources. Taghvaei and Jafari (2015) reviewed all the available research from 1997 to 2007 on application and stability of natural antioxidants (plant and animal sources) in edible oil in comparison with synthetic. They pointed out that besides the high effectiveness of the natural antioxidant against degradation in edible oils, sourcing for their raw materials are quite cheaper than the synthetic ones. A market survey conducted over the span of nine years (2000-2009) on the $€ 15$ million European antioxidant market, estimated 35 per cent compound growth rate for natural antioxidants (Thorat et al., 2013). This subsequently led to the genesis of sourcing for cheap natural source of antioxidants which are as effective as their synthetic counterparts.

Rehman (2006) has reported that by-products from fruit and vegetable processing had been the major source of natural antioxidants used in ensuring oil stability during storage and food pro- cessing. Nonetheless, contrary to popular opinion, epidemiological studies and literature have established that cereal grains have high phenolic antioxidant distribution in their outer layers, as much as fruit and vegetable by-products (Masisi, Beta \& Moghadasian, 2016). Madhujith and Shahidi (2009) compared the antioxidant properties of different fractions of barley varieties using the Trolox equivalent antioxidant capacity (TEAC) assay on phenolic extracts. The results for TEAC showed that outermost layer of the barley grains for the varieties exhibited higher antioxidant capacity range (9.11$69.30 \mu \mathrm{mol}$ of Trolox equiv/g of defatted material) than the innermost fraction $(0.45-7.85 \mu \mathrm{mol}$ of Trolox equiv/g of defatted material). (Huang \& Lai, 2016) also reported that red and black rice bran showed a similar trend of high range of antioxidant capacity (6.69-14.55, 18.94-49.99 mg Trolox equiv/g of defatted material) using DDPH antioxidant assay. However, there are limited reports on the application of these cereal brans as natural antioxidants to improve oil stability during frying.

The aim of this study is to compare the effectiveness of three cereal bran extracts (black rice, millet and barley) as natural sources of antioxidants with a synthetic antioxidant (propyl gallate) against oil degradation during frying.

\section{Materials and Methods}

\subsection{Samples and chemicals used}

Whole grain black rice, millet and barley were kindly supplied by Healthy food suppliers West 
Sussex, UK. Sunflower vegetable oil was obtained from a local Sainsbury store, Greater London, UK. All chemicals purchased were analytical grade (Fischer scientific and Sigma-aldrich)

\subsection{Preparation of the bran}

The barley, millet and rice bran were obtained following the procedure described by Arab, Alemzadeh and Maghsoudi (2011) with minor adjustments. A Kenwood grain mill (A941PK005/P, Havant UK) was used to mill the barley, millet and rice wholegrain, respectively and a 2.5-inch fine plastic mesh strainer was used to sieve the bran from the resulting flour. All brans were stored in a sealed plastic container immediately, except for the rice bran which was subjected to stabilization. The stabilization was carried out as described by Arab et al. (2011). The rice bran was then cooled at room temperature overnight and stored at $4{ }^{\circ} \mathrm{C}$ until further analyses.

\subsection{Extraction of phenolic extracts from the grain bran}

The extraction was done according to the procedure described by Lai, Li, Lu and Chen (2009). Five grams of barley, millet and stabilized rice bran were extracted with $20 \mathrm{ml}$ (ratio 1:4) each of three different solvents, namely methanol, ethanol and ethyl acetate in an electric orbital shaker (55rpm; Stuart S5105, UK) at room temperature for (3) three hours. This was followed by filtration of the extract through $250 \mathrm{~mm}$ of Fisher's filter paper and the residue was reextracted twice, then the filtrate was dried under vacuum using a rotary evaporator (Stuart RE301P, UK) at $50^{\circ} \mathrm{C}$. The percentage extract yield was calculated using the equation (1) below:

$$
E Y=\frac{\left(W_{\text {after drying }}-W_{\text {before drying }}\right)}{\text { Actual weight of sample }} \times 100
$$

Where EY = Extraction Yield (\%) W = weight of the round bottom flask.

\subsection{Dermination of total phenolic content in the methanolic bran extracts}

The total phenolic content of the bran extracts was determined using the Folin-Ciocalteu reagent method as described by Singleton and A. Jr. Rossi (1965). Results were calculated as Gallic acid equivalents ( $\mathrm{mg} / \mathrm{g}$ of bran) in triplicate.

\subsection{Determination of total antioxidant capacity of the methanolic extracts by Trolox Equivalent Antioxidant Capacity (TEAC) assay}

Antioxidant capacity of the bran extracts was assayed based on the decolourisation 2,2'azinobis-(3-ethylbenzothiazoline-6-sulphonate) radical cation $\left(\mathrm{ABTS}^{+}\right)$as described by $\mathrm{Re}$ et al. (1999) with major adjustments in the preparation of radical cation stock and working solution. The radical cation $\left(\mathrm{ABTS}^{+}\right)$stock solution was produced by reacting $50 \mathrm{ml}$ of $7 \mathrm{mM}$ aqueous solution ABTS (in distilled water) with $50 \mathrm{ml}$ of $2.45 \mathrm{mM}$ potassium persulphate $\left(\mathrm{K}_{2} \mathrm{~S}_{2} \mathrm{O}_{8}\right)$ in the dark at room temperature for 16 hours in ratio (1:1). The working solutions were then prepared daily by diluting $1 \mathrm{ml}$ of the stock solution with $43 \mathrm{ml}$ of the extracting solvent (Methanol) to give $0.70 \pm 0.05$ absorbance at $734 \mathrm{~nm}$ using a UV Visible Spectrophotometer (JK-UVS-752N,Jinke Scientific, Shanghai).

The standard calibration curve was prepared using a concentration range of $0-250 \mu \mathrm{M}$ from $2.5 \mathrm{Mm}$ of trolox stock solution. This major adjustment was verified for consistency by taking the absorbance of 0,100 and $200 \mu \mathrm{M}$ in triplicate before the taking the measurement for the sample. $1.5 \mathrm{ml}$ of ABTS radical solution was mixed with $100 \mu \mathrm{l}$ of extract sample or standard solution and measured at $734 \mathrm{~nm}$ after 6 minutes. The observed absorbance for the sample or the standard were expressed as percentage inhibition in triplicates using equation (2) below:

$$
\text { Inhibition } \%=\frac{\left(A_{\text {blank }}-A_{\text {extracts }}\right)}{A_{\text {blank }}} \times 100
$$


Where $A_{\text {blank }}=$ Absorbance observed for blank after 6 minutes

$\mathrm{A}_{\text {extracts }}=$ Absorbance observed for extracts after 6 minutes

The standard curves were constructed using the inhibition $\%$ as a function of trolox concentration and the results for the sample extracts were expressed as Trolox equivalents in terms of $\mu \mathrm{molTE} / \mathrm{g}$ of the sample.

\subsection{Enrichment of the sunflower oil with the synthetic and natural antioxidant}

200ppm of propyl gallate was measured according to the codex regulation on the maximum amount of synthetic antioxidant required in edible oil. 1000ppm each of dried rice, barley and MBE were carefully measured and added to the $100 \mathrm{ml}$ of the sunflower oil in three different Duran bottles. Also, the control sample oil was prepared with no antioxidant addition. The resulting enriched vegetable oils were homogenized for even distribution of the added extracts by using a high-performance homogenizer (Ultra Turexx, T 25.IKA USA) at 7000rpm for $7 \mathrm{~min}$ and the resulting stock oils were added to $900 \mathrm{ml}$ of the frying oil in the fryer. $100 \mathrm{ml}$ of each enriched oil sample and control sample were measured and stored at $-4^{\circ} \mathrm{C}$ until further analyses.

\subsection{Frying procedure}

To compare the effectiveness of the added antioxidant extracts in the vegetable oil during frying, a standard black-eyed pea paste was made by mixing black eyed pea flour with a 2:1 ratio in water: $100 \mathrm{~g}$ of black eyed-pea flour with $50 \mathrm{~g}$ of water. $25 \mathrm{~g}$ of the resulting mixture was rolled into balls and two of balls were fried in each enriched oil sample using a deep fat fryer (Tefal FR333040 fryer, J.C Campbell electrics, Northern Ireland). The oils were heated to $175 \pm 2^{\circ} \mathrm{C}$, then black eyed pea balls were fried once for 9 minutes and oil was cooled for 6 minutes. $100 \mathrm{ml}$ of each oil sample was taken immediately after the cooling of the oil. The frying and cooling processes were repeated five (5) times throughout the frying process. Sample oils were collected after each process (15, 30, 45, 60 and 75 minutes) and stored at $-4^{\circ} \mathrm{C}$ until further analyses.

\subsection{Chemical analysis of the oil}

The free fatty acid content of the oil samples taken during frying was measured. This is a titrimetric method that was done according to the official procedure described by AOCS Ca 5a40 (1998). The free fatty acid content of the oil samples was expressed in percentage. Also, the conjugated diene and total polar content of the oil samples taken during frying were measured. These were carried out according to the standard method described by AOCS Ti la-64 (1998) and $\mathrm{Xu}$ (2000) respectively. Both oil stability parameters were measured in percentage

\subsection{Data analysis}

All data were expressed in mean \pm standard deviation and chemical characteristics analyses were subjected to one- way ANOVA (IBM SPSS Statistics for Windows, Version 24.0. Armonk, NY: IBM Corp) and Post hoc test (Tukey HSD) at significance $95 \%$ confidence level $\mathrm{p}<0.05)$

\section{Results and Discussion}

\subsection{Extraction of phenolic extracts from the grain bran}

The methanol extraction (Table 1) proved more efficient, showing an extract yield $(\%)$ of about two times higher than the ethanol and ethyl acetate extractions, respectively. Millet bran gave the highest range of extract yield among the three extraction solvents whilst barley bran seems to have the lowest yield results.

The better extract yield shown by methanol can be attributed to high polarity of the solvent ( $\mathrm{Po}-$ larity: methanol $>$ ethanol $>$ ethyl acetate) and the functional group of the polar compounds present in the bran. The extract yields for this study were not as high as the range of results (13.2-20.16\% and 7.85-16.3\%) reported by Arab 
et al. (2011) and Lai et al. (2009). However, the results pattern for each extraction solvent were similar, that is; methanol gave the highest yield extracts from all three brans.

\subsection{Determination of total phenolic content in the methanolic bran extracts}

The total phenolic content for the rice, millet and BBE reported in Table 2 showed that the result for rice bran is approximately three times higher than that of the MBE and five times higher than the result for BBE.

The better results recorded by the rice bran was due to the high level of pigment (proanthocyanidin and anthocyanin) in the bran compared to the other bran extracts. The main rationale behind the low output could be attributed to the solid-solvent extraction method used for the bran which is effective only for the free phenolic compounds in the bran, which are usually in low amount compared to the conjugated and insoluble bound phenolic compounds that might be present in the bran (Madhujith \& Shahidi, 2009). The TPC results for rice bran from this study was significantly higher than the range results $(35 \pm 0.01-7.14 \pm 0.60 \mathrm{mg} \mathrm{GAE} / \mathrm{g})$ reported by Moongngarm, Daomukda and Khumpika (2012) for varieties of black rice bran.

\subsection{Determination of total antioxidant capacity of the methanolic extracts by Trolox Equivalent Antioxidant Capacity (TEAC) Assay}

The results described in Table 3 showed that the antioxidant activity for barley bran and rice bran extract are two times higher than that of millet bran extract $(17.16 \pm 0.34$ Trolox equivalent $\mu \mathrm{mol} / \mathrm{g}$ of bran). Moreover, the barley bran extract (40.95 \pm 0.07 Trolox equivalent $\mu \mathrm{mol} / \mathrm{g}$ of bran) showed the best antioxidant activity, higher than the RBE (40.87 \pm 0.04 Trolox equivalent $\mu \mathrm{mol} / \mathrm{g}$ of bran).

The high antioxidant activity recorded for BBE was consistent within the range of TEAC results
(9.11- $69.30 \mu \mathrm{mol}$ of Trolox equiv/g of defatted material) reported by Madhujith, Izydorczyk and Shahidi (2006) for the outermost layer (bran) for two varieties of barley.

\subsection{Determination of the free fatty acid content of the frying oil samples}

The results for the free fatty acid content in the oil samples during frying (Table 4) showed that all the free fatty acid content for the enriched oil samples and the control at all frying times except at $0,15,30$ minutes were all significantly different from each other. It is further explained that, at 0 minutes, the Rice Bran extract enriched oil samples were not significantly different from the PG enriched oil sample, and at 15 minutes and 30 minutes Barley bran extract enriched, and Millet bran extract enriched, and control oil samples followed the same trend, respectively. Overall results after 75 minutes of frying showed that the PG enriched oil had a free fatty acid content $(1.62 \pm 0.00 \%)$ approximately four times lower than that of the control sample $(6.13 \pm 0.01 \%)$, almost two times lower than the FFA in both MBE and BBE $(3.43 \pm 0.01$ and $3.13 \pm 0.01 \%)$ enriched oil and $0.4 \%$ lower than the FFA found in RBE enriched oil samples. Free fatty acids in oil during frying are products of hydrolysis that occur as soon the food materials are immersed in the oil at high temperature. The amount of these compounds in oil is directly proportional to the rate of oxidation that occurred at the propagation step (formation of hydroxyl peroxide radical from the oil molecule) in the degradation of oil molecules by increasing the rate at which atmospheric oxygen (initiator of the propagation step) from the headspace dissolve in the oil (Choe \& Min, 2007).

As expected, the FFA will increase with the frying time, but the legal maximum percentage of the FFA should not exceed $2 \%$ otherwise the oil should be replaced. Farahmandfar, Asnaashari and Sayyad (2015) reported a range of results slightly like the results for this present study. The FFA content from this present study showed that the RBE enriched oil samples are effective for frying food materials for 1 hour 15 minutes 
\begin{tabular}{l|l} 
Effectiveness of cereal bran extract for sunflower oil stability during frying & SI57
\end{tabular}

Table 1: Extraction yield (\%) of three different solvents on the rice, millet and barley bran

\begin{tabular}{lccc}
\hline Sample & Methanol & Ethanol & Ethyl-acetate \\
\hline Rice & $4.2 \pm 0.05$ & $2.8 \pm 0.03$ & $2.8 \pm 0.12$ \\
Millet & $11.4 \pm 0.21$ & $4.8 \pm 0.01$ & $4.4 \pm 0.11$ \\
Barley & $3.0 \pm 0.15$ & $1.6 \pm 0.13$ & $1.4 \pm 0.02$ \\
\hline \multicolumn{2}{c}{ Note: All results are reported in mean \pm standard deviation }
\end{tabular}

Table 2: The total phenolic distribution in the various cereal extracts

\begin{tabular}{lc}
\hline Extracts & $\begin{array}{c}\text { Total phenolic content } \\
(\mathrm{mg} \text { Gallic acid/g of bran })\end{array}$ \\
\hline Rice bran & $18.58 \pm 0.71$ \\
Millet bran & $6.94 \pm 0.23$ \\
Barley bran & $3.96 \pm 0.12$ \\
\hline Note: All results are reported in mean \pm standard deviation
\end{tabular}

Table 3: Antioxidant activities of the cereal bran extracts

\begin{tabular}{lc}
\hline Extracts & Trolox equivalent $\mu \mathrm{mol} / \mathrm{g}$ of bran \\
\hline Rice bran & $40.87 \pm 0.04$ \\
Millet bran & $17.16 \pm 0.34$ \\
Barley bran & $40.95 \pm 0.07$ \\
\hline \multicolumn{2}{c}{ Note: All results are reported in mean \pm standard deviation }
\end{tabular}

compared with the other extract enriched oils without replacing the oil, but not as effective as the synthetic antioxidant $(\mathrm{PG})$ enriched oil.

\subsection{Conjugated diene content of the frying oil samples}

The conjugated diene content in oil is a reliable indicator to monitor the oxidative deterioration in oil during frying as it measures the primary oxidation products (conjugated diene/trienes) in the oil samples. These are secondary oxidation products of the degradation of oil that cause offcolor and odour that affect the quality characteristics of the oil. The conjugated diene content (\%) reported in Table 5 showed that all the enriched oil samples and the control at all frying times except at 0 minutes are significantly different from each other. The result further explained at 0 minutes, $\mathrm{BBE}$ and $\mathrm{MBE}$ are not significantly different from each other. The overall con- jugated diene content results for all oil samples after 1 hour 15 minutes showed that the control oil sample had the highest results $(70.00 \pm 0.16$ $\%$ ) while the results for RBE enriched oil was approximately two times lower than that of $\mathrm{BBE}$ enriched oil sample and about $17.49 \%$ on average lower than that of MBE and PG enriched oil samples, respectively.

The implication of the abovementioned results means that the RBE was effective as a natural antioxidant, forming a stable compound with the lipid hydro-peroxide radical, thus preventing rapid degradation of the compounds to secondary oxidation products. This can potentially be attributed to $\gamma$ oryzanol, which has been identified as the major antioxidative phenolic compound in black rice bran (Shin et al., 2017). Chen et al. (2016) reported the effectiveness of $\gamma$ oryzanol against degradation of primary and secondary oxidation products, which would otherwise result in off-colour and odour. There is no 
SI58 Ajala and Ghavami

Table 4: Free fatty acid content for the oil samples at various frying times

\begin{tabular}{lccccc}
\hline $\begin{array}{l}\text { Frying Time } \\
\text { (minutes) }\end{array}$ & Control & RBE & MBE & BBE & PG \\
\hline 0 & $0.49 \pm 0.01^{a}$ & $0.22 \pm 0.14^{b}$ & $0.32 \pm 0.01^{c}$ & $0.60 \pm 0.00^{d}$ & $0.23 \pm 0.21^{b}$ \\
15 & $0.92 \pm 0.01^{a}$ & $0.40 \pm 0.00^{b}$ & $1.23 \pm 0.14^{c}$ & $1.22 \pm 0.14^{c}$ & $0.62 \pm 0.14^{d}$ \\
30 & $1.86 \pm 0.01^{a}$ & $1.31 \pm 0.14^{b}$ & $1.93 \pm 0.01^{c}$ & $1.83 \pm 0.01^{a}$ & $0.92 \pm 0.01^{d}$ \\
45 & $3.77 \pm 0.22^{a}$ & $1.61 \pm 0.01^{b}$ & $2.33 \pm 0.02^{c}$ & $2.22 \pm 0.01^{c}$ & $1.23 \pm 0.01^{b}$ \\
60 & $5.11 \pm 0.01^{a}$ & $1.91 \pm 0.00^{b}$ & $2.92 \pm 0.01^{c}$ & $2.31 \pm 0.01^{d}$ & $1.42 \pm 0.01^{e}$ \\
75 & $6.13 \pm 0.01^{a}$ & $2.02 \pm 0.01^{b}$ & $3.43 \pm 0.01^{c}$ & $3.13 \pm 0.01^{d}$ & $1.62 \pm 0.00^{e}$ \\
\hline
\end{tabular}

Results are expressed as mean \pm standard deviation.

Means followed by different superscripts show a significant difference $(\mathrm{p}<0.05)$ between

the values in rows for each frying time.

RBE: Rice bran Extract, MBE: Millet bran extracts, BBE: Barley bran extracts,

PG: Propyl gallate.

Table 5: Conjugated diene content for the oil samples at various frying times

\begin{tabular}{|c|c|c|c|c|c|}
\hline $\begin{array}{l}\text { Frying Time } \\
\text { (minutes) }\end{array}$ & Control & $\mathrm{RBE}$ & MBE & $\mathrm{BBE}$ & PG \\
\hline 0 & $39.37 \pm 0.21^{a}$ & $17.13 \pm 0.03^{b}$ & $25.71 \pm 0.63^{c}$ & $26.31 \pm 0.30^{c}$ & $36.56 \pm 0.41^{d}$ \\
\hline 15 & $48.22 \pm 0.15^{a}$ & $23.19 \pm 0.06^{b}$ & $25.81 \pm 0.63^{c}$ & $34.45 \pm 0.17^{d}$ & $38.95 \pm 0.12^{e}$ \\
\hline 30 & $52.29 \pm 0.14^{a}$ & $27.71 \pm 0.56^{b}$ & $37.68 \pm 0.12^{c}$ & $51.77 \pm 0.21^{d}$ & $43.94 \pm 0.63^{e}$ \\
\hline 45 & $63.41 \pm 0.04^{a}$ & $31.01 \pm 0.17^{b}$ & $36.32 \pm 0.04^{c}$ & $56.98 \pm 0.08^{d}$ & $47.96 \pm 0.04^{e}$ \\
\hline 60 & $68.25 \pm 0.03^{a}$ & $32.14 \pm 0.24^{b}$ & $50.03 \pm 0.36^{c}$ & $58.98 \pm 0.06^{d}$ & $50.97 \pm 0.02^{e}$ \\
\hline 75 & $70.00 \pm 0.16^{a}$ & $34.28 \pm 0.18^{b}$ & $51.17 \pm 0.29^{c}$ & $63.14 \pm 0.00^{d}$ & $52.36 \pm 0.08^{e}$ \\
\hline
\end{tabular}

Results are expressed as mean \pm standard deviation

Means followed by different superscripts show a significant difference $(\mathrm{p}<0.05)$ between

the values in rows for each frying time.

RBE: Rice bran Extract, MBE: Millet bran extracts, BBE: Barley bran extracts,

PG: Propyl gallate.

legal maximum percentage for conjugated diene in used oil samples, but the high value recorded for this present study was an indication of a high degree of degradation in oil samples since the presence of conjugated diene in the oil primarily means oxidation has occurred. Different researchers have attributed an increase in conjugated diene with frying time, temperature, the unsaturation level of the fatty acid composition of the oil (Aydeniz \& Yilmaz, 2012).These further explained the high value recorded for the oil characterization carried out in this present study because the value increased with the frying time and the polyunsaturated fatty acids (PUFAs) of the sunflower oil used for this experiment was $69 \mathrm{~g}$ per100g of oil.

\subsection{Total polar material content for the frying oil samples}

The total polar material content in oil is the sum of non-volatile polymerized compounds usually by-products of hydrolysis, oxidation, condensation and all other complex reactions that occur during degradation of oil during frying (Tompkins \& Perkins, 2000). This is also an imperative, monitoring extent of oxidative degradation, reusability and quality of oil (Aydeniz \& Yilmaz,

\begin{tabular}{l|l|l|l} 
IJFS & January 2020 & Volume 9 & pages SI52-SI61
\end{tabular} 
\begin{tabular}{l|l|l} 
Effectiveness of cereal bran extract for sunflower oil stability during frying & SI59
\end{tabular}

Table 6: Total polar material content for the frying oil samples

\begin{tabular}{|c|c|c|c|c|c|}
\hline $\begin{array}{l}\text { Frying Time } \\
\text { (minutes) }\end{array}$ & Control & $\mathrm{RBE}$ & MBE & $\mathrm{BBE}$ & $\mathrm{PG}$ \\
\hline 0 & $2.72 \pm 0.02^{a}$ & $6.29 \pm 0.09^{b}$ & $6.34 \pm 0.01^{b}$ & $5.48 \pm 0.01^{c}$ & $2.98 \pm 0.01^{d}$ \\
\hline 15 & $2.75 \pm 0.03^{a}$ & $6.17 \pm 0.04^{b}$ & $5.96 \pm 0.02^{c}$ & $5.39 \pm 0.05^{d}$ & $3.04 \pm 0.05^{e}$ \\
\hline 30 & $2.84 \pm 0.04^{a}$ & $5.69 \pm 0.06^{b}$ & $5.36 \pm 0.04^{c}$ & $5.18 \pm 0.11^{d}$ & $3.04 \pm 0.05^{e}$ \\
\hline 45 & $2.88 \pm 0.01^{a}$ & $5.55 \pm 0.08^{b}$ & $4.92 \pm 0.00^{c}$ & $5.12 \pm 0.02^{d}$ & $3.21 \pm 0.05^{e}$ \\
\hline 60 & $2.94 \pm 0.01^{a}$ & $5.38 \pm 0.04^{b}$ & $4.68 \pm 0.01^{c}$ & $4.99 \pm 0.00^{d}$ & $3.17 \pm 0.01^{e}$ \\
\hline 75 & $3.03 \pm 0.03^{a}$ & $5.08 \pm 0.10^{b}$ & $4.57 \pm 0.04^{c}$ & $4.76 \pm 0.00^{c}$ & $3.21 \pm 0.02^{d}$ \\
\hline
\end{tabular}

Results are expressed as mean \pm standard deviation.

Means followed by different superscripts show a significant difference $(p<0.05)$ between

the values in rows for each frying time.

RBE: Rice bran Extract, MBE: Millet bran extracts, BBE: Barley bran extracts,

PG: Propyl gallate.

2016). The TPM results for this study reported in Table 6 explained that the values were all significantly different from each other across the frying time except for 0 and 75 minutes. The overall results showed that control samples contained TPM values lower than the synthetic $(P G)$ and other extract enriched oils while the RBE enriched oil had the highest content of polar compounds $(5.08 \pm 0.10 \%)$. However, none of the extract enriched oil samples exceeded the maximum legal limit of $25 \%(\mathrm{Xu}, 2000)$. The general low amount of polar material for all samples was consistent with the results reported by Karakaya and Simsek (2011) using the same frying time intervals for four different varieties of oil and recording an average TPM of approximately $5 \%$. It is interesting to note that, the total polar material for $\mathrm{RBE}, \mathrm{MBE}$ and $\mathrm{BBE}$ enriched oil samples were high at 0 minutes and tended to decrease as the frying time increased. This phenomenon can be explained by the high pigmented nature of oil when the extracts were added and, as the frying time proceeded, there was a gradual reduction in the colour of the oil samples. Since the TPM value for the oil samples was measured using spectrophotometry methods, the observed absorbance for each oil sample decreases as the frying time increases. This similar decrease in TPM was also reported by Lee, Lee, Lee, Park and Choe (2002) where they evaluated the effect of different proportions $(5 \%, 15 \%$ and $25 \%$ ) of spinach powder on degradation of soybean oil at $160^{\circ} \mathrm{C}$ for 24 hours.

\section{Conclusions}

From this study, the methanolic extraction gave the highest extract yield from the three solvents; Methanolic extracts of rice bran contained the highest distribution of phenolic compounds while methanolic extracts of barley bran exhibited the better antioxidant activity, slightly higher than that of RBE.

The application of these methanolic extracts to sunflower oil samples during frying showed that RBE was more effective than the other extract brans and as effective as the synthetic antioxidant (propyl gallate) against degradation of oil during frying.

Summarily, RBE can be used as a potential natural antioxidant source to fry black-eyed pea balls for 1-hour 15 minutes without replacing or replenishing the oil and with around $90 \%$ of its (rice bran) world production been used as animal feedstock and landfills, it would be a potential economical source and represent sustainable usage as a natural antioxidant.

\section{Acknowledgements}

We would like to thank London Metropolitan University for the use of their facilities for this 
research. We would also wish to thank Mr John Morgan and Mr Arun Rajan for their unwavering commitment and technical support received during this study.

\section{References}

Aladedunye, A. F., Matthäus, B. \& Przybylski, R. (2011). Correction to: Carbon dioxide blanketing impedes the formation of 4-hydroxynonenal and acrylamide during frying. a novel procedure for hne quantification. European Journal of Lipid Science and Technology, 113, 916-923. doi:10.1002/ ejlt.201100021

AOCS Ca 5a-40. (1998). Free fatty acids. official methods and recommended practices of the american oil chemists' society (aocs). champaign, il, usa: Aocs press.

AOCS Ti la-64. (1998). Spectrophotometric determination of conjugated dienoic acid. Official Methods and Recommended Practices of the American Oil Chemists' Society (AOCS). Champaign, IL, USA: AOCS Press.

Arab, F., Alemzadeh, I. \& Maghsoudi, V. (2011). Determination of antioxidant component and activity of rice bran extract. Scientia Iranica, 18(6), 1402-1406. doi:10.1016/j . scient.2011.09.014

Aydeniz, B. \& Yilmaz, E. (2012). Enrichment of frying oils with plant phenolic extracts to extend the usage life. European Journal of Lipid Science and Technology, 114 (8), 933941. doi:10.1002/ejlt.201100228

Aydeniz, B. \& Yilmaz, E. (2016). Performance of different natural antioxidant compounds in frying oil. Food Technology and Biotechnology, 54 (1), 21-30.

Chen, X.-W., Chen, Y.-J., Wang, J.-M., Guo, J., Yin, S.-W. \& Yang, X.-Q. (2016). Phytosterol structured algae oil nanoemulsions and powders: Improving antioxidant and flavor properties. Food \& function, 7(9), 3694-3702.

Choe, E. \& Min, D. B. (2007). Chemistry of deep-fat frying oils. Journal of Food Science, 72(5), R77-R86. doi:10.1111/j.17503841.2007.00352.x
Farahmandfar, R., Asnaashari, M. \& Sayyad, R. (2015). Comparison antioxidant activity of tarom mahali rice bran extracted from different extraction methods and its effect on canola oil stabilization. Journal of Food Science and Technology-mysore, 52(10), 6385-6394. doi:10 . 1007 / s13197 014-1702-2

Huang, Y.-P. \& Lai, H.-M. (2016). Bioactive compounds and antioxidative activity of colored rice bran. Journal of Food and Drug Analysis, 24(3), 564-574. doi:10.1016/j . jfda.2016.01.004

Karakaya, S. \& Simsek, S. (2011). Changes in total polar compounds, peroxide value, total phenols and antioxidant activity of various oils used in deep fat frying. Journal of the American Oil Chemists Society, 88(9), 1361-1366. doi:10.1007/s11746-0111788- $\mathrm{x}$

Lai, P., Li, K. Y., Lu, S. \& Chen, H. H. (2009). Phytochemicals and antioxidant properties of solvent extracts from japonica rice bran. Food Chemistry, 117(3), 538-544. doi:10. 1016/j.foodchem.2009.04.031

Lee, J., Lee, S., Lee, H., Park, K. \& Choe, E. (2002). Spinach (spinacia oleracea) powder as a natural food-grade antioxidant in deep-fat-fried products. Journal of Agricultural and Food Chemistry, 50(20), 56645669. doi:10.1021/jf011618a

Madhujith, T., Izydorczyk, M. \& Shahidi, F. (2006). Antioxidant properties of pearled barley fractions. Journal of Agricultural and Food Chemistry, 54(9), 3283-3289. doi:10.1021/jf0527504

Madhujith, T. \& Shahidi, F. (2009). Antioxidant potential of barley as affected by alkaline hydrolysis and release of insolublebound phenolics. Food Chemistry, 117(4), 615-620. doi:10.1016/j.foodchem.2009.04. 055

Masisi, K., Beta, T. \& Moghadasian, M. H. (2016). Antioxidant properties of diverse cereal grains: A review on in vitro and in vivo studies. Food Chemistry, 196, 90-97. doi:10.1016/j.foodchem.2015.09.021

Moongngarm, A., Daomukda, N. \& Khumpika, S. (2012). Chemical compositions, phytochemicals, and antioxidant capacity of rice 
Effectiveness of cereal bran extract for sunflower oil stability during frying $\mid$ SI61

bran, rice bran layer, and rice germ. In Y. Dan (Ed.), 3rd international conference on biotechnology and food science (icbfs 2012) (Vol. 2, pp. 73-79). APCBEE Procedia. 3rd International Conference on Biotechnology and Food Science (ICBFS), Bangkok, THAILAND, APR 07-08, 2012. doi:10.1016/j.apcbee.2012.06.014

Okubo, T., Yokoyama, Y., Kano, K. \& Kano, I. (2003). Cell death induced by the phenolic antioxidant tert-butylhydroquinone and its metabolite tert-butylquinone in human monocytic leukemia u937 cells. Food and Chemical Toxicology, 41(5), 679-688. doi:10.1016/S0278-6915(02)00002-4

Pokorny, J., Yanishlieva, N. \& Gordon, M. H. (2001). Antioxidants in food: Practical applications. CRC press.

Re, R., Pellegrini, N., Proteggente, A., Pannala, A., Yang, M. \& Rice-Evans, C. (1999). Antioxidant activity applying an improved abts radical cation decolorization assay. Free Radical Biology and Medicine, 26 (9-10), 1231-1237. doi:10.1016/S0891$5849(98) 00315-3$

Rehman, Z. (2006). Citrus peel extract-a natural source of antioxidant. Food Chemistry, 99(3), 450-454. doi:10.1016/j. foodchem. 2005.07.054

Shin, S. Y., Kim, H.-W., Jang, H.-H., Hwang, Y.-J., Choe, J.-S., Lim, Y., ... Lee, Y. (2017). Gamma-oryzanol-rich black rice bran extract enhances the innate immune response. Journal of Medicinal Food, 20. doi:10.1089/jmf.2017.3966

Singleton, V. l. \& A. Jr. Rossi, J. (1965). Colorimetry of total phenolics with phosphomolybdic-phosphotungstic acid reagents. American Journal of Enology and Viticulture, 16(3), 144-158.

Sumnu, S. G. \& Sahin, S. (2008). Advances in deep-fat frying of foods. CRC Press.

Taghvaei, M. \& Jafari, S. M. (2015). Application and stability of natural antioxidants in edible oils in order to substitute synthetic additives. Journal of Food Science and Technology-mysore, 52(3), 1272-1282. doi:10.1007/s13197-013-1080-1

Thorat, I. D., Jagtap, D. D., Mohapatra, D., Joshi, D. C., Sutar, R. F. \& Kapdi, S. S.
(2013). Antioxidants, their properties, uses in food products and their legal implications. International Journal of Food Studies, 2(1), 81-104. doi:10.7455/ijfs / 2.1. 2013.a7

Tompkins, C. \& Perkins, E. G. (2000). Frying performance of low-linolenic acid soybean oil. Journal of the American Oil Chemists Society, 77(3), 223-229. doi:10.1007/ s11746-000-0036-2

Xu, X. Q. (2000). A new spectrophotometric method for the rapid assessment of deep frying oil quality. Journal of the American Oil Chemists Society, 77(10), 1083-1086. doi:10.1007/s11746-000-0170-x 